Research Paper

\title{
Proton-sensing GPCR-YAP Signalling Promotes Cell Proliferation and Survival
}

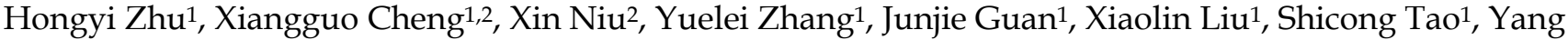 \\ Wang ${ }^{1,2,}$, Changqing Zhang $1,2, \bowtie$
}

1. Department of Orthopaedic Surgery, Shanghai Jiaotong University Affiliated Sixth People's Hospital, Shanghai 200233, China.

2. Institute of Microsurgery on Extremities, Shanghai Jiaotong University Affiliated Sixth People's Hospital, Shanghai 200233, China.

$\triangle$ Corresponding authors: Tel: +86 21 64369181; Fax: +86 216470 1361; Email: zhangcq@sjtu.edu.cn (Changqing Zhang); Tel: +86 18930174249; Fax: +86 216470 1361; Email: wangy63cn@126.com (Yang Wang)

(C) 2015 Ivyspring International Publisher. Reproduction is permitted for personal, noncommercial use, provided that the article is in whole, unmodified, and properly cited. See http://ivyspring.com/terms for terms and conditions.

Received: 2015.04.25; Accepted: 2015.07.01; Published: 2015.08.08

\begin{abstract}
The $\mathrm{pHs}$ of extracellular fluids (ECFs) in humans are consistently maintained at 7.35 to 7.45 in physiological conditions. Pathological changes, including infarction, tumourigenesis and inflammation, commonly result in decreases in the ECF pH in the affected tissues. In this study, we report that proliferation is promoted and apoptosis is inhibited by decreases in extracellular $\mathrm{pH}$. Furthermore, we demonstrated that proton-sensing G-protein-coupled receptors (GPCRs) are required for the $\mathrm{pH}$-dependent regulation of proliferation and apoptosis through the $\mathrm{G}$ protein $\alpha$ subunit 12/13 (G12/13) and Rho GTPases. Next, we identified Yes-associated protein 1 (YAP) as a downstream effector of Rho signalling. Together, the results from our study demonstrate that extracellular $\mathrm{pH}$ can modulate cell proliferation and apoptosis by regulating the proton-sensing GPCR-YAP pathway.
\end{abstract}

Key words: pH, YAP, proton-sensing, GPCR, proliferation, apoptosis

\section{Introduction}

The $\mathrm{pHs}$ of extracellular fluids (ECFs) are a basic property of the tissue microenvironment and are normally maintained between 7.35 and 7.45 by the regulation of respiration and renal acid extrusion. For in vitro cultured cells, the $\mathrm{pH}$ of the culture medium is also maintained in a narrow range of approximately 7.40. Decreases in ECF pH are observed in ischaemic, tumorous and inflammatory tissues [1-3]. Acidification of the ECF regulates a wide range of cellular functions, including cell adhesion [4], neurogenesis [5], insulin secretion [6], smooth muscle contraction [7] and inflammatory cytokine production [8-10]. Interestingly, the effects of acidification on proliferation and apoptosis are controversial [11-15].

The molecular mechanisms by which cells sense and adapt to extracellular $\mathrm{pH}$ changes are not completely understood. Proton-sensing GPCRs, including GPR4 [16], GPR65 [11], GPR68 [17] and GPR132 [18], form a group of GPCRs that are activated in response to decreases in extracellular $\mathrm{pH}$. Proton-sensing GPCRs sense neutral or weakly acidic pHs that are generally in the range of 6 to 8 through histidine residues [19]. Unlike the proton-sensing ionotropic channels that are primarily expressed by neurons, proton-sensing GPCRs are expressed by non-neuronal cells and thereby have been recognized as important cell $\mathrm{pH}$-sensors. Previous studies have discovered that GPR68 is typically coupled with Gq/11 and that GPR4, GPR65 and GPR132 are coupled with Gs [20, 21]. Gq/11 and Gs subsequently activate the phospholipase $\mathrm{C} / \mathrm{Ca}^{2+}$ signalling pathway and the adenylyl cyclase/cAMP signalling pathway, respectively, to modulate cellular functions. Additionally, extracellular acidification leads to the activation of the Rho signalling pathway through GPR4 and G12/13 [22, 23].

In the present study, we report that decreases in extracellular $\mathrm{pH}$ lead to increases in the proliferation 
and decreases in apoptosis of cells with abundant proton-sensing GPCR expression and that these effects can be blocked by the inhibition of Rho signalling. Finally, we identify YAP, a potent oncoprotein, as an important effector downstream of proton-sensing GPCRs.

\section{Materials and methods}

\section{Cell isolation and culture}

The use of human bone marrow-derived stromal cells (BMSCs) and articular chondrocytes (ACs) in this study was approved by the ethics committee of Shanghai Jiaotong University and the consent of the donors was obtained. The BMSCs and ACs were isolated from healthy donors (age 30-50 years old) who underwent amputation due to severe trauma. Briefly, cancellous bone and articular cartilage were obtained during the operations. The cancellous bone was first flushed with culture medium and then transferred to a T75 container. The BMSCs were isolated by adherence. Articular chondrocytes were dissociated from the foetal cartilage using $0.1 \%$ Collagenase II in DMEM/F12 for 24 hours and then isolated by adherence. The BMSC and AC surface markers were routinely examined by flow cytometry (Guava). The BMSCs and HEK293T were cultured in high-glucose DMEM (Invitrogen) with 10\% FBS (Gibco). The human microvascular endothelial cells (HMVECs), human endometrial cancer cells, and human breast cancer cells (MDA-MB-453) were cultured with RPMI-1640 (Corning) with 5\% FBS. The SKOV-3s and ACs were cultured with DMEM/F12 (Corning) with $10 \%$ FBS. Media of different $\mathrm{pH}$ values were prepared via the addition of $1 \mathrm{M} \mathrm{HCl}$ or $1 \mathrm{M} \mathrm{NaOH}$ to supplemented complete medium after $\mathrm{pH}$ equilibrium in the incubator for 24 hours. The media were replaced every $12 \mathrm{~h}$ to ensure the stability of the extracellular $\mathrm{pHs}$ in the specific conditions.

\section{RNA Extraction, Reverse Transcription and Real-Time PCR}

RNA samples were prepared using Trizol (Invitrogen) according to a standard protocol. The RNA integrity and quantity were analysed with a NanoDrop 2000. Reverse transcription was performed using the Transcript First Strand cDNA Synthesis Kit (Roche). Real-time PCR was performed using FS Universal SYBR Green Master (Roche) on the ABI 7900HT (Applied Biosystems) and analysed with SDS 2.4 (Applied Biosystems). Each experiment was performed at least three times. GAPDH was used as a housekeeping gene for the normalisation of the results of this study. The detailed information about the primers is as follows:
hCTGF-FOR: TGTGCACCGCCAAAGATGG

hCTGF-REV: ACGTGCACTGGTACTTGCAG

hCyr61-FOR: AAGGAGCTGGGATTCGATGC

hCyr61-REV: CATTCCAAAAACAGGGAGCCG

hANKRD1-FOR: AGCCCAGATCGAATTCCGTG hANKRD1-REV: TGAGCAACTTATCTCGGGCG hGAPDH-FOR: GATGGGTGGAGTCGCGTG hGAPDH-REV: CGCCCAATACGACCAAATCAGA GA

hGPR68-FOR: CCTCACCTGGTTGCAGAGAC hGPR68-REV: GACCCCCACCTGTGCTTTC

\section{Lentivirus infection and RNA interference}

All lentiviruses and siRNAs for RNA interference were obtained from Genepharm. For infection, the cells were incubated in retroviral supernatant with $5 \mu \mathrm{g} / \mathrm{mL}$ polybrene for $24 \mathrm{~h}$. Forty-eight hours after infection, the cells were selected with $2.5 \mu \mathrm{g} / \mathrm{mL}$ puromycin (Sigma-Aldrich) in culture medium. For siRNA transfection, the cells were transfected with siRNA-Mate (Genepharm) according to the manufacturer's instructions. The siRNA sequences used in this study were the following: siGPR68 \#1, 5'CCAGCAUCUACUUCCUGAUTT -3'; and siGPR68 \#2, 5'- GUACCAUCGACCAUACCAUTT -3'. The shRNA sequences used in this study were the following: shYAP \#1, 5'- CTGGTCAGAGATACTTC TTAA -3'; and shYAP \#2, 5'- AAGCTTTGAG TTCTGACATCC $-3^{\prime}$.

\section{Immunoblotting analysis}

The cells were lysed using Cellytic M (Sigma-Aldrich) for $30 \mathrm{~min}$ on ice. Cell lysates were centrifuged for $15 \mathrm{~min}$ at $15000 \times \mathrm{g}$. Immunoblotting was performed using standard SDS-PAGE protocols. YAP (\#14074), p-S127 (\#13008), ROCK1 (\#4035), LATS1 (\#3477), p-T1079 (\#8654), p-S909 (\#9157), MYPT1 (\#5143), p-T853 (\#4563) and GAPDH (\#5174) antibodies were obtained from Cell Signaling Technology.

\section{BrdU incorporation}

The cells were plated on 24-well plates at similar densities. Fresh media with different $\mathrm{pHs}$ were added to the cells. After $24 \mathrm{~h}$, the cells were incubated with $10 \mu \mathrm{M}$ BrdU for $1 \mathrm{~h}$ and stained with anti-BrdU antibody (Cell Signaling Technology) according to manufacturer's instructions. The cells were then incubated with anti-mouse Alexa Fluor594-conjugated secondary antibodies for flow cytometry analysis (Guava). The BrdU (\#5292) antibody was purchased from Cell Signaling Technology.

\section{Cell viability analysis}

Media of different $\mathrm{pHs}$ were added to the cells. After $24 \mathrm{~h}$ of incubation, the cells were incubated with $10 \mu \mathrm{M}$ camptothecin (MedChem Express) for $6 \mathrm{~h}$ to 
induce apoptosis. Cell viability was then analysed using a LIVE/DEAD Fixable Green Dead Cell Stain Kit (Molecular Probe) or an Annexin V/PI apoptotic analysis kit (Cell Signalling Technology) according to the manufacturers' instructions.

\section{Immunofluorescence staining}

For the immunofluorescence staining, the cells were cultured on coverslips to similar densities using media of different $\mathrm{pHs}$. The cells were fixed and then permeabilized. After blocking in 10\% FBS for $2 \mathrm{~h}$, the cells were incubated with primary antibody for $2 \mathrm{~h}$ at room temperature. After washing with PBS three times, the cells were incubated with Alexa Fluor-conjugated secondary antibodies for $2 \mathrm{~h}$. The cells were then washed with PBS three times prior to observation. Microscopic images were captured using a Leica DMI6000 B with Leica AF6000 software. YAP mouse antibodies (MR0635, UCallM) and GPR68 (sc-98437, Santa Cruz) antibodies were used for staining.

\section{CCK-8 assay}

The cells were plated in 96-well plates at a density of $2 \times 10^{3}$ cells/well. At each time point, the cells were incubated with $10 \mu \mathrm{l} \mathrm{CCK-8} \mathrm{reagent} \mathrm{in} 100 \mu \mathrm{l}$ fresh culture medium for 3 hours at $37^{\circ} \mathrm{C}$. The absorbance was measured at the wavelength of $450 \mathrm{~nm}$. Each experiment was performed in triplicate.

\section{Animals}

Six-weeks-old male nude mice were maintained in SPF conditions. SKOV-3 $\left(5 \times 10^{6}\right)$ and MDA-MB-453

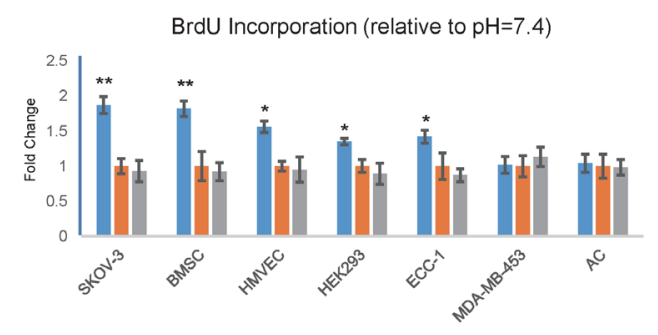

C

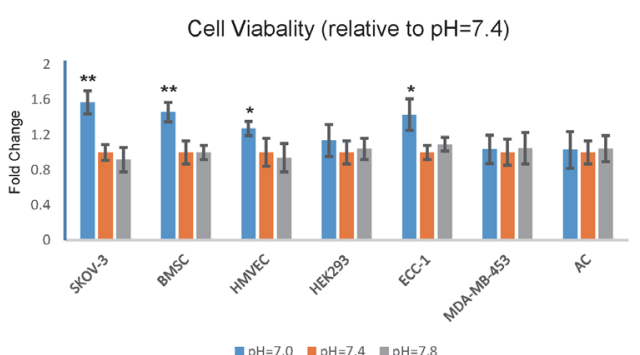

B

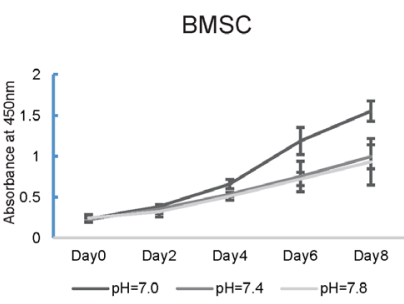

D

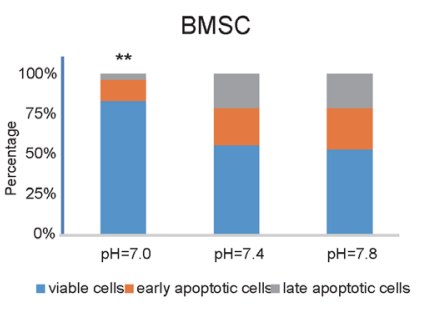

$\left(5 \times 10^{6}\right)$ cells suspended in equal volumes of $50 \%$ Matrigel (diluted with DMEM/F12) were injected subcutaneously into the nude mice. The mice were treated daily with simvastatin $(5 \mathrm{mg} / \mathrm{kg})$ that was homogenously prepared in vegetable oil via intragastric injections for 1 month. The tumour volumes were calculated according to the following: volume $=0.5 \times(\text { width })^{2} \times$ length .

\section{Results}

\section{Decreases in extracellular $\mathrm{pH}$ promoted pro- liferation and inhibited apoptosis}

To examine the relationship between extracellular $\mathrm{pH}$ and proliferation, BrdU incorporation assays were performed on SKOV-3, BMSC, HMVEC, HEK293T, ECC-1, MDA-MB-453 and AC cells (Fig. 1A). Surprisingly, we did not observe any cell lines that exhibited decreased growth rates in response to acidic pHs. We performed CCK-8 assays on the BMSCs and SKOV-3s to further confirm our previous observations (Fig. 1B). Next, we induced apoptosis with camptothecin, which is a common apoptotic inducer, and tested cell viability in different extracellular pHs (Fig. 1C). Interestingly, the MDA-MB-453s and ACs also exhibited insensitivity to $\mathrm{pH}$ changes, whereas the other cells demonstrated reduced apoptosis in response to the decrease in extracellular $\mathrm{pH}$. Annexin V/PI staining was then conducted, and consistent results were observed (Fig. 1D). Taken together, our results indicated that decreases in extracellular $\mathrm{pH}$ promote the proliferation and inhibit apoptosis in some cell lines. 


\section{Proton-sensing GPCRs in the regulation of proliferation and apoptosis through the Rho signalling pathway}

We next investigated whether proton-sensing GPCRs were involved in the $\mathrm{pH}$-dependent regulation of proliferation and apoptosis. We examined the gene expressions of proton-sensing GPCRs in all of the cell types. Interestingly, one or more GPCRs were abundantly expressed by each of the $\mathrm{pH}$-sensitive cells in the SKOV-3, BMSCs, HMVEC, HEK293T, and ECC-1 lines, whereas none of the known proton-sensing GPCRs were expressed by the pH-insensitive MDA-MB-453s and ACs (Fig. 2A).

GPR68 is the sole proton-sensing GPCR that is abundantly expressed by BMSCs, and RNA interference with GPR68 in the BMSCs led to the loss of sensitivity to decreases in extracellular $\mathrm{pH}$ (Fig. 2B and Fig. 2C). Consistently, transgenic expression of GPR68 in the MDA-MB-453 cells endowed them with the capability to responding to acidic extracellular $\mathrm{pH}$ (Fig. 2D and Fig. 2E). Our observations suggested that proton-sensing GPCRs were necessary for the $\mathrm{pH}$-dependent promotion of cell survivals and proliferation.

We treated cells with botulinum toxin C3 and Y27632, which are specific inhibitors of Rho GTPases and ROCK, respectively, with the purpose of interfering with Rho signalling. Strikingly, despite the different expression patterns of the proton-sensing GPCRs in the different cells, the inhibition of Rho signalling, which is a known downstream pathway of G12/13, resulted in the blocking of the enhancements of cell survival and proliferation in all of the $\mathrm{pH}$-sensitive cell lines in acidic extracellular $\mathrm{pHs}$ (Fig. $2 \mathrm{~F}$ and Fig. 2G). Our findings suggested that Rho signalling might be the common downstream pathway by which different proton-sensing GPCRs control cell death and growth.
A

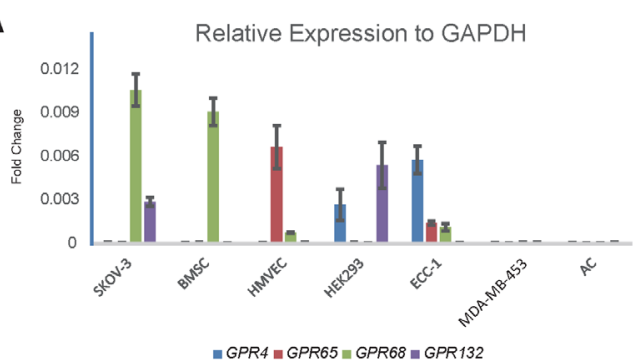

B

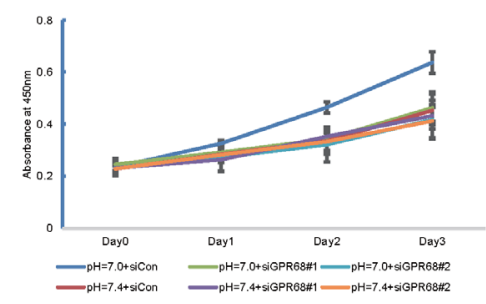

E

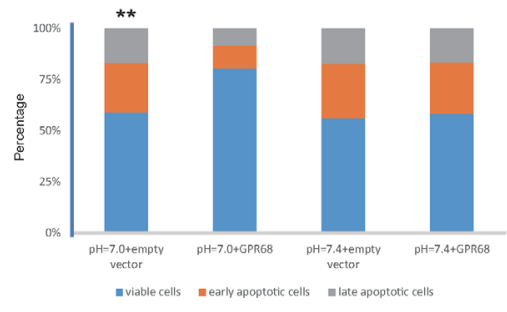

C

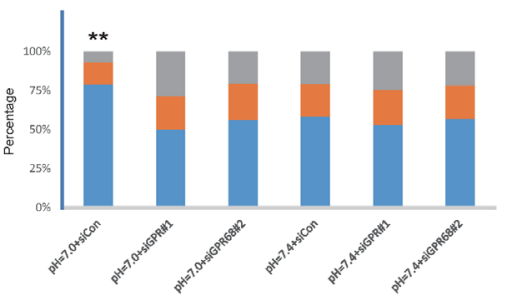

$\mathbf{F}$

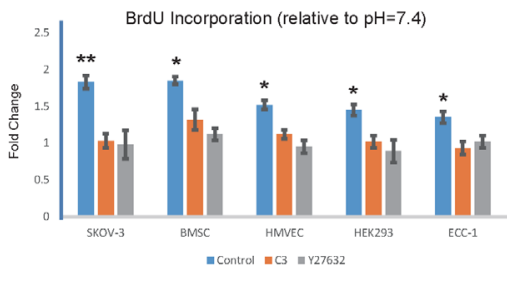

G

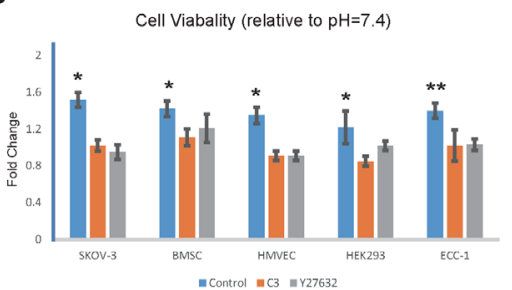

Figure 2. Proton-sensing GPCRs in regulation of proliferation and apoptosis through Rho signalling pathway (A) mRNA levels of indicated proton-sensing GPCRs in different cell lines. (B) Knockdown of GPR68 blocks PH-dependent regulation on proliferation and apoptosis. Proliferation of BMSCs transfected with control siRNA or GPR68 siRNA was assessed by CCK-8. (C) Apoptosis was induced with 10uM camptothecin on BMSCs transfected with control siRNA or GPR68 siRNA respectively. Annexin V/PI assays were then conducted. (D) Transgenic expression of GPR68 endows cells with capabilities of responding to acidic extracellular $\mathrm{pH}$. ACs were transfected with empty vector or GPR68 vector. Proliferation was assessed by CCK-8 assays. (E) Apoptosis was induced with $10 \mu \mathrm{M}$ camptothecin and then assessed by Annexin $\mathrm{V} / \mathrm{PI}$ staining. (F) Rho signalling is required for $\mathrm{pH}$-dependent regulation on proliferation and apoptosis. Cells were treated with the Rho inhibitor C3 $(3 \mu \mathrm{g} / \mathrm{mL})$ and the ROCK inhibitor $\mathrm{Y} 27632(50 \mathrm{mM})$ in medium with different $\mathrm{pH}(\mathrm{pH}=7.0$ or $\mathrm{pH}=7.4)$ for 24 hours. BrdU incorporation assay was then conducted. (G) Apoptosis was induced with $10 \mathrm{uM}$ camptothecin and then assessed by live/dead cell staining in different cell lines at different $\mathrm{pH}(\mathrm{pH}=7.0$ or $\mathrm{pH}=7.4)$. All experiments were performed at least 3 times in triplicate. Error bars represent the SEM. Statistical analysis was performed using one-way ANOVA followed by Student's T test. *P $<0.05$; **P $<0.01(\mathrm{C})$ versus $\mathrm{pH}=7.4+$ siCon. $(\mathrm{E})$ versus $\mathrm{pH}=7.4+\mathrm{empty}$ vector. $(\mathrm{F}, \mathrm{G})$ versus control. 


\section{Decreases in extracellular $\mathrm{pH}$ result in YAP activation}

Next, we explored the downstream effector of proton-sensing GPCR signalling that promotes cell survival and proliferation. Recent progress has indicated that GPCR-Rho signalling can dephosphorylate and thereby activate YAP [24, 25]. Based on the well-established oncogenic role of YAP, we hypothesized that YAP is the downstream effector of proton-sensing GPCRs that drives cell proliferation and survival. Western blotting analysis revealed that a decrease in extracellular $\mathrm{pH}$ induced the dephosphorylation of YAP (Fig. 3A), which resulted in its dissociation from 14-3-3 and subsequent nuclear localization [26-28]. The nuclear localization of YAP, which promotes cell survival and proliferation via binding to TEAD family transcription factors [29], was observed in the immunofluorescence assays (Fig. 3C). Additionally, we observed the accumulation of YAP with longer exposure times to the acidic $\mathrm{pH}$ conditions (Fig. 3B). CTGF, Cyr61 and ANKRD1 are well-characterized YAP downstream genes [30]. The expressions of these YAP target genes were significantly upregulated by a decrease in extracellular $\mathrm{pH}$ (Fig. 3D). Based on the above observations, we concluded that YAP can be activated in response to acidic extracellular $\mathrm{pH}$.

A

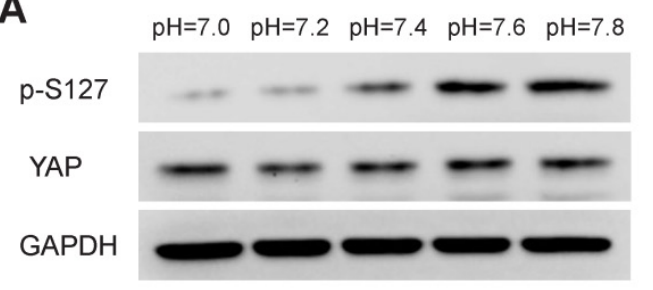

C

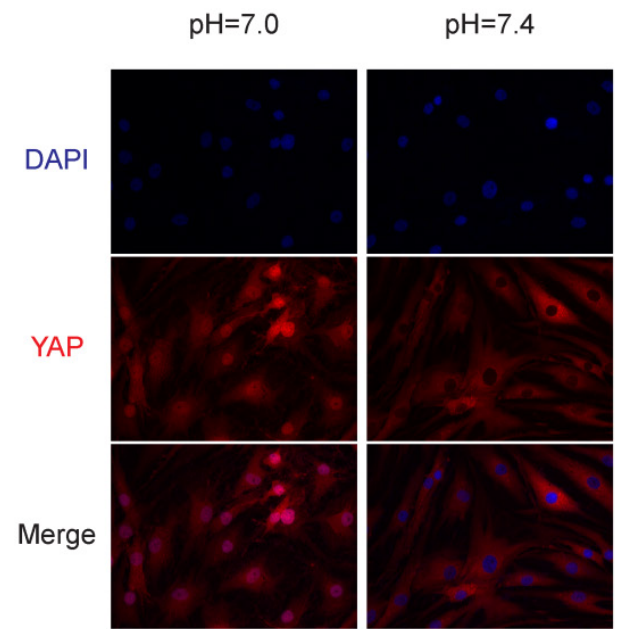

\section{Proton-sensing GPCR-Rho signalling regulates YAP activity}

Next, we investigate the role of Rho signalling in $\mathrm{pH}$-dependent YAP regulation. We first assessed the kinase activities of ROCK and LATS in low extracellular $\mathrm{pH}$ conditions. The phosphorylation of MYPT1, which is a substrate of ROCK, was promoted, and the phosphorylation of LATS, which leads to the inactivation of YAP, was repressed when cultured at low $\mathrm{pH}$ (Fig. 4A). We then inhibited Rho signalling with botulinum toxin C3 and Y27632 treatment, which interferes with YAP dephosphorylation in acidic extracellular pHs (Fig. 4B). YAP localization was also assessed after Rho signalling interference (Fig. 4C). The silencing of GPR68 blocked the nuclear localization and activation of YAP in low pH conditions (Fig. 4D). Consistently, the transgenic expression of GPR68 in ACs resulted in the nuclear translocation of YAP in acidic extracellular $\mathrm{pH}$ conditions, and the inhibition of Rho signalling with $\mathrm{C} 3$ and $\mathrm{Y} 27632$ resulted in the retention of YAP in the cytoplasm (Fig. 4E). YAP activity was not related to the expression levels of proton-sensing GPCRs when cells are cultured at normal $\mathrm{pH}$ (Fig. S1A and Fig. S1B). Our findings indicated that $\mathrm{pH}$-dependent YAP activity is regulated by GPCR-Rho signalling.

B

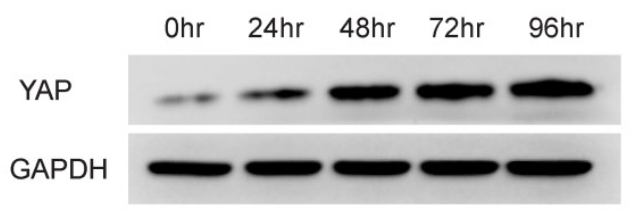

D

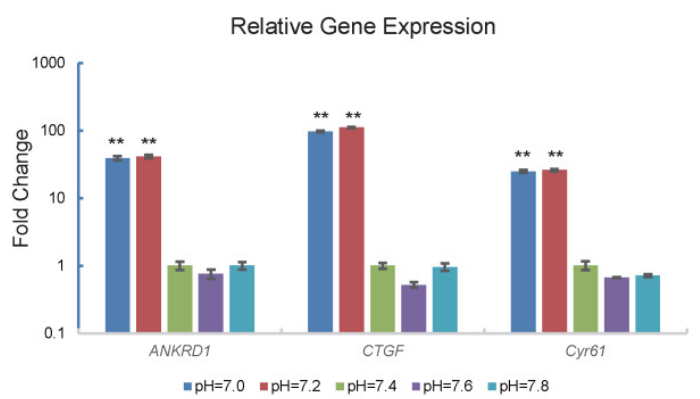

Figure 3. Decrease in $\mathrm{pH}$ induces activation of YAP (A) Decrease in extracellular pH induces YAP dephosphorylation. HEK293 cells were stimulated with respective culture medium ( $\mathrm{pH}$ as indicated) for three hours (B) Decrease in extracellular $\mathrm{pH}$ results in $\mathrm{YAP}$ accumulation. HMVEC cells were treated with culture medium at $\mathrm{pH}=7.0$ for different time as indicated. (C) Decrease in $\mathrm{pH}$ induces YAP nuclear localization in MSCs. MSCs were stimulated with culture medium at indicated pH for 3 hours. YAP subcellular localization was then monitored. (D) Expression of YAP target genes increases in response to decrease in extracellular $\mathrm{pH}$. SKOV-3 cells were cultured at indicated $\mathrm{pH}$ for 24 hours and then mRNA level of YAP target genes were assessed. All experiments were performed at least 3 times (every time in triplicate for qPCR). Error bars represent the SEM. Statistical analysis was performed using one-way ANOVA followed by Student's T test. **P $<0.01(\mathrm{C})$ versus $\mathrm{pH}=7.4$. 


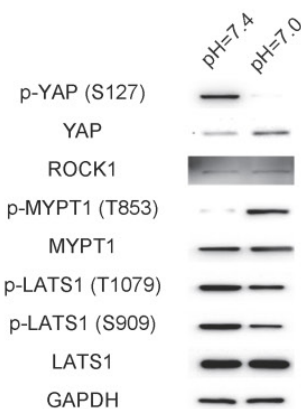

C

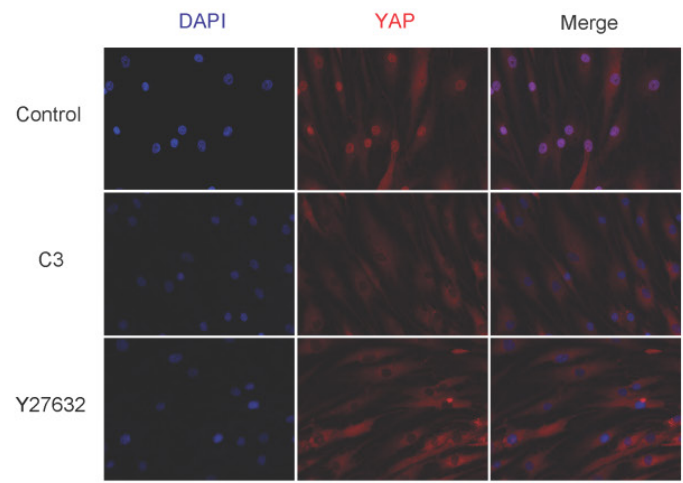

B

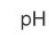

$\mathrm{p}-\mathrm{S} 127$

YAP

GAPDH

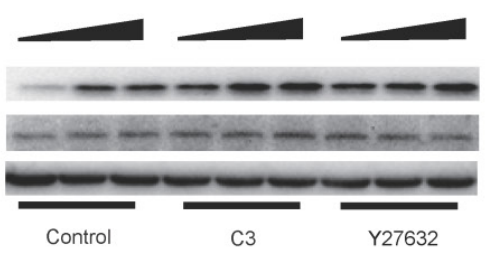

D

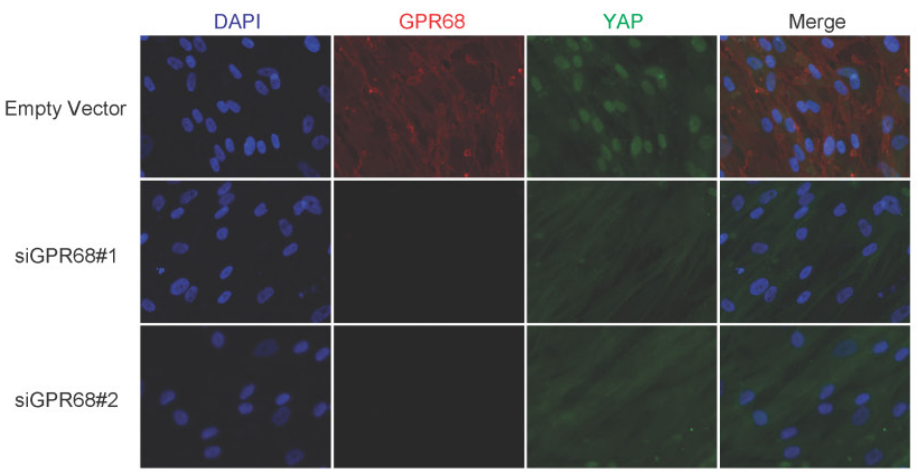

E

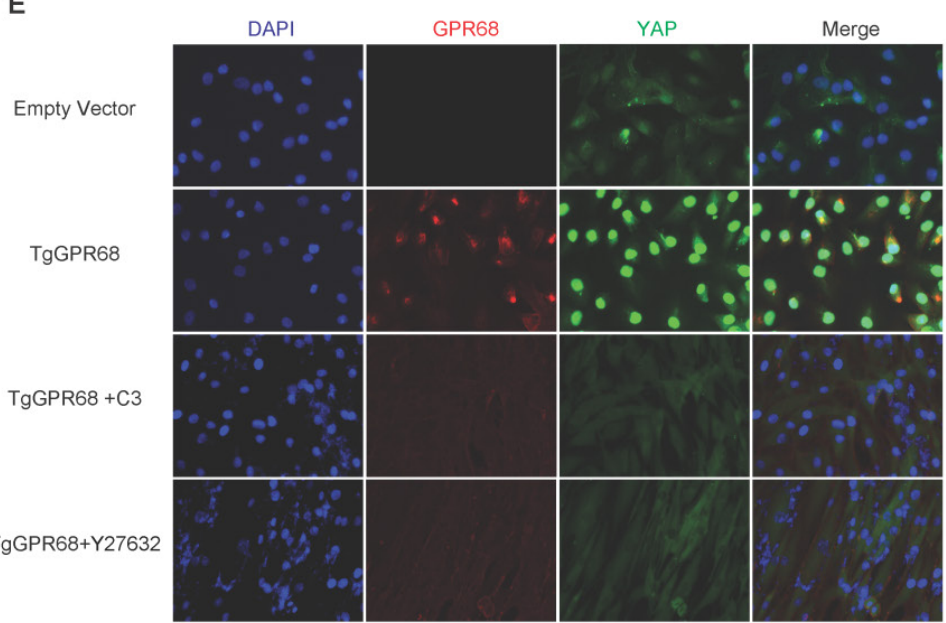

Figure 4. Regulation of GPCR-Rho signalling on YAP activities (A) Low extracellular PH activates ROCK kinase while inhibits LATS kinase. The activity of ROCK kinase was monitored by phosphorylation of MYPT1, a substrate of ROCK kinase. Phosphorylation of LATS1 at T1079 and S909 which results in inhibition of LATS kinase was repressed by low extracellular $\mathrm{pH}$. (B) Inhibition of Rho signalling interferes with dephosphorylation of YAP in response to decreased extracellular $\mathrm{pH}$. ECC-1 cells were cultured at high cell density and then treated with $\mathrm{C} 3(3 \mu \mathrm{g} / \mathrm{mL})$ and $\mathrm{Y} 27632(50 \mathrm{mM})$ in medium with low $\mathrm{pH}(\mathrm{pH}=7.0)$ for 3 hours. (C) Nuclear localization of YAP induced by low extracellular $\mathrm{pH}$ is blocked by inhibition of Rho signalling. BMSCs were cultured at high cell density and then treated with $\mathrm{C} 3(3 \mu \mathrm{g} / \mathrm{mL})$ and $\mathrm{Y} 27632(50 \mathrm{mM})$ at $\mathrm{pH}=7.0$ for 3 hours. (D) Knockdown of GPR68 blocks pH-dependent regulation on YAP. BMSCs transfected with control siRNA or GPR68 siRNA and cultured at pH=7.0 for 3 hours. (E) ACs were transfected with empty vector or GPR68 vector and cultured at $\mathrm{pH}=7.0$ for 3 hours. $\mathrm{C} 3(3 \mathrm{\mu g} / \mathrm{mL})$ and $\mathrm{Y} 27632(50 \mathrm{mM})$ were treated as indicated. All experiments were performed at least 3 times.

\section{YAP is required for proton-sensing GPCR-signalling to regulate proliferation and apoptosis}

Finally, to further investigate the effects of YAP activation on proliferation and apoptosis, we used viral shRNA to knockdown YAP expression. Decreases in extracellular $\mathrm{pH}$ were no longer able to promote the growth rate and cell survival of YAP-silenced cells (Fig. 5A and Fig. 5B). Based on these observations, we concluded that YAP is essential for the enhanced cell proliferation and survival 
that is driven by decreases in extracellular $\mathrm{pH}$. Recent progress has demonstrated inhibitory effects of statins on YAP [31]. Consistently, we also observed potent inhibitory effects of multiple statins on YAP (Fig. S2). The promotion of the growth rate and cell survival induced by low $\mathrm{pH}$ was blocked after statin treatment (Fig. 5C and Fig. 5D). Next, we successfully sup- pressed tumour growth with statin therapy in vivo (Fig. 5E). However, statins were more effective against $\mathrm{pH}$-sensitive cancer cells than $\mathrm{pH}$-insensitive cells. Given the long history of their clinical application, statins could be the most promising candidate for a novel cancer therapy.
A

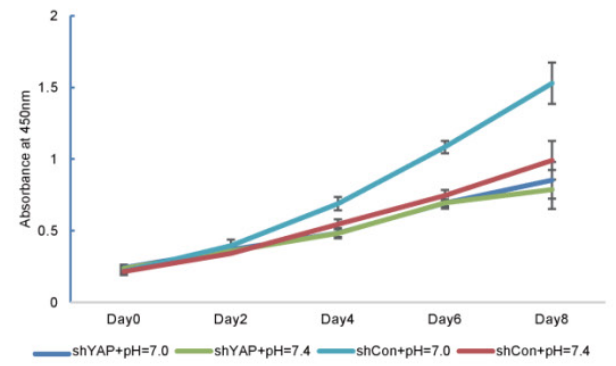

B

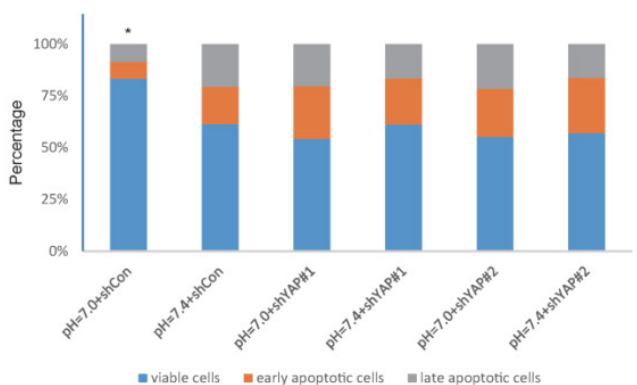

c

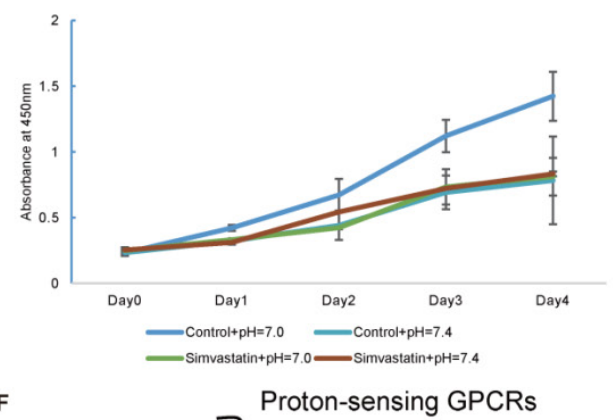

กెก

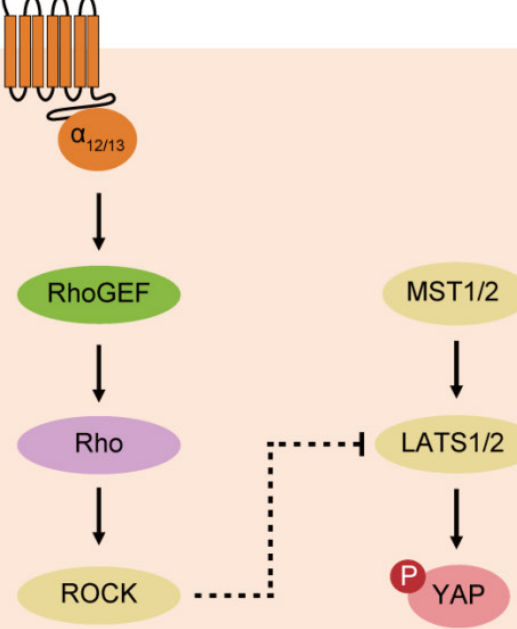

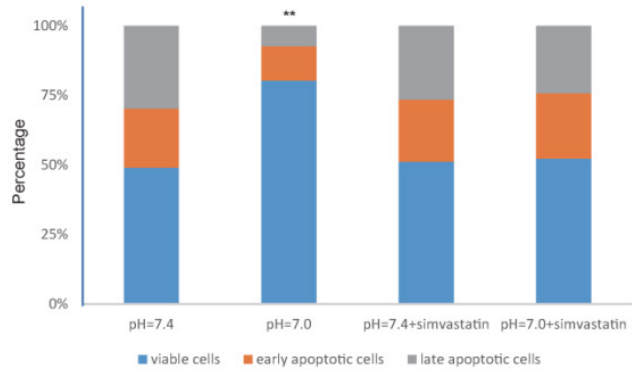

E
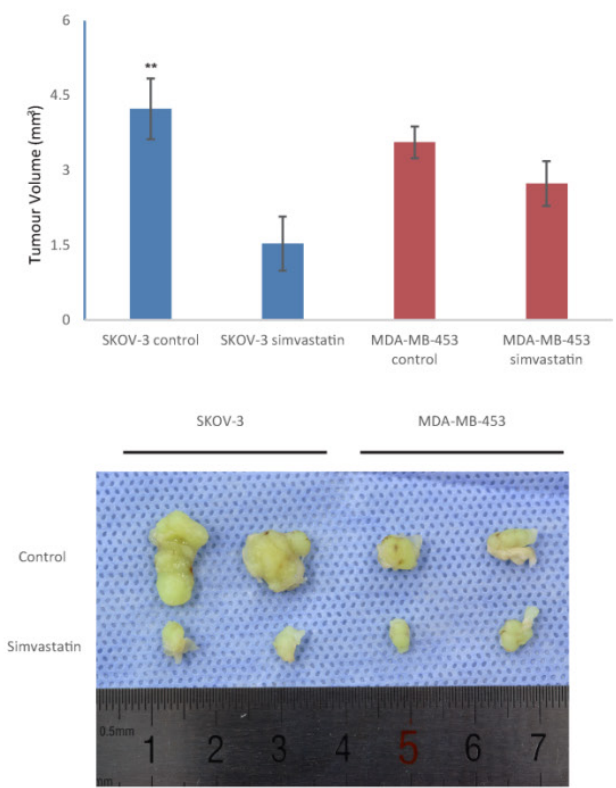

Cytoplasm

Nucleus

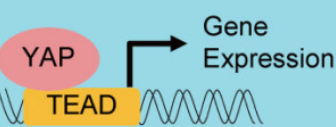

Figure 5. YAP is the effector of proton-sensing GPCR-signalling to regulate proliferation and apoptosis (A) Knockdown of YAP blocks $\mathrm{pH}$-dependent regulation on cell proliferation. HMVECs infected with control shRNA or YAP shRNA were cultured at indicated $\mathrm{pH}$. (B) Knockdown of YAP inhibits prevention of decreased extracellular $\mathrm{pH}$ to apoptosis. HEK293 cells infected with control shRNA or YAP shRNA were cultured at indicated $\mathrm{pH}$. Apoptosis was induced by camptothecin (10uM) for 12 hours and assessed by Annexin V/PI staining. (C) Simvastatin inhibits increased proliferation in response to low $\mathrm{pH}$. Simvastatin was treated at 10uM. (D) Inhibition of apoptosis by low $\mathrm{pH}$ is rescued by simvastatin $(10 \mu \mathrm{M})$.

(E) Simvastatin given to nude mice $(n=6)$ at a dose of $5 \mathrm{mg} / \mathrm{kg}$ via intragastric administration significantly inhibits the xenograft growth of tumors compared to control group. (F) A proposed model for proton-sensing GPCRs and $G$ proteins in the regulation of YAP activity and subsequent proliferation and apoptosis. All experiments were performed at least 3 times. Error bars represent the SEM. Statistical analysis was performed using one-way ANOVA followed by Student's T test. $* \mathrm{P}<0.05$; $* * \mathrm{P}$ $\begin{array}{ll}<0.01 & \text { (B) versus }\end{array}$ $\mathrm{pH}=7.4+$ shCon. (D) versus $\mathrm{pH}=7.4$. (E) versus control. 


\section{Discussion}

Acidic microenvironments caused by lactate production accompany almost all pathological circumstances. Under ischemic and inflammatory circumstances, anaerobic glycolysis is stimulated due to hypoxia and causes lactate production. Cancer cells preferentially metabolize glucose to lactate as the main fuel source even when oxygen is plentiful, and this process is termed the Warburg Effect. Thus, it is important to determine the effects of acidic ECF on cells. This study primarily focused on cell proliferation and apoptosis, which are especially important in cancer research. Our data revealed pro-proliferative and anti-apoptotic roles of acidic extracellular microenvironments. The unlimited proliferation potential and the Warburg effect in cancer cells result in the acidification of the extracellular environment, which further stimulates proliferation. It is urgent to study the underlying proton-sensing mechanisms to break this viscous circle.

The discoveries of proton-sensing GPCRs extended proton-sensing mechanisms from neurons to other cells. However, the GPCR signalling is rather complicated due to the expression of multiple receptors for protons and the differential functions of $G$ proteins. Thus, attempts to target single proton-sensing GPCRs might be futile for therapy due to compensation provided by GPCRs. Instead, the targeting of downstream mediators and effectors of proton-sensing GPCRs might be a more reasonable strategy. We identified Rho-YAP signalling as the common downstream pathway of the proton-sensing GPCRs that control cell proliferation and survival. We then inhibited the growth of xenograft tumours by targeting YAP with statins. Our evidence suggests that statins might be a novel and potent therapy for cancers, especially those expressing proton-sensing GPCRs.

In addition to proliferation and apoptosis, YAP also regulates cell migration $[32,33]$ and differentiation $[30,34]$. It is possible that extracellular acidification might also influence such cell behaviours through proton-sensing GPCR-YAP signalling. Future investigations are needed to address these important biological issues.

\section{Supplementary Material}

Figures S1-S2. http://www.ijbs.com/v11p1181s1.pdf

\section{Acknowledgement}

This study was supported by the Special Fund for Healthy Scientific Research in the Public Interest, China (201402016).

\section{Authors' contributions}

C.Z., Y.W. and H.Z. designed the experiments and analysed the data. H.Z. performed the main part of the experiments. X.N. and X.C. isolated the BMSCs and ACs. S.T. and J.G. performed all of the qPCR detections. X.L. conducted all of the flow cytometry detections. Y.Z. was responsible for all of the CCK-8 assays. H.Z. conducted the rest of the experiments. C.Z. and H.Z. wrote the manuscript.

\section{Competing interests} interests.

The authors declare that they have no competing

\section{References}

1. Goldie I, Nachemson A. Synovial pH in rheumatoid knee joints. II. The effect of local corticosteroid treatment. Acta orthopaedica Scandinavica. 1970; 41: 354-62.

2. Khan T, Soller B, Naghavi M, Casscells W. Tissue $\mathrm{pH}$ determination for the detection of metabolically active, inflamed vulnerable plaques using near-infrared spectroscopy: an in-vitro feasibility study. Cardiology. 2005; 103: $10-6$.

3. Schornack PA, Gillies RJ. Contributions of cell metabolism and $\mathrm{H}+$ diffusion to the acidic $\mathrm{pH}$ of tumors. Neoplasia. 2003; 5: 135-45.

4. Chen A, Dong L, Leffler NR, Asch AS, Witte ON, Yang LV. Activation of GPR4 by acidosis increases endothelial cell adhesion through the cAMP/Epac pathway. PloS one. 2011; 6: e27586.

5. Schneider JW, Goetsch SC, Leng X, Ludwig SM, Russell JL, Yang CP, et al. Coupling hippocampal neurogenesis to brain $\mathrm{pH}$ through proneurogenic small molecules that regulate proton sensing $G$ protein-coupled receptors. ACS chemical neuroscience. 2012; 3: 557-68.

6. Nakakura T, Mogi C, Tobo M, Tomura H, Sato K, Kobayashi M, et al. Deficiency of proton-sensing ovarian cancer $\mathrm{G}$ protein-coupled receptor 1 attenuates glucose-stimulated insulin secretion. Endocrinology. 2012; 153: 4171-80.

7. Saxena H, Deshpande DA, Tiegs BC, Yan H, Battafarano RJ, Burrows WM, et al. The GPCR OGR1 (GPR68) mediates diverse signalling and contraction of airway smooth muscle in response to small reductions in extracellular $\mathrm{pH}$. British journal of pharmacology. 2012; 166: 981-90.

8. Mogi C, Tobo M, Tomura H, Murata N, He XD, Sato K, et al. Involvement of proton-sensing TDAG8 in extracellular acidification-induced inhibition of proinflammatory cytokine production in peritoneal macrophages. Journal of immunology. 2009; 182: 3243-51.

9. He XD, Tobo M, Mogi C, Nakakura T, Komachi M, Murata N, et al. Involvement of proton-sensing receptor TDAG8 in the anti-inflammatory actions of dexamethasone in peritoneal macrophages. Biochemical and biophysical research communications. 2011; 415: 627-31.

10. Dong L, Li Z, Leffler NR, Asch AS, Chi JT, Yang LV. Acidosis activation of the proton-sensing GPR4 receptor stimulates vascular endothelial cell inflammatory responses revealed by transcriptome analysis. PloS one. 2013; 8: e61991.

11. Li Z, Dong L, Dean E, Yang LV. Acidosis decreases c-Myc oncogene expression in human lymphoma cells: a role for the proton-sensing $G$ protein-coupled receptor TDAG8. International journal of molecular sciences. 2013; 14: 20236-55.

12. Ihara $Y$, Kihara $Y$, Hamano F, Yanagida K, Morishita Y, Kunita A, et al. The G protein-coupled receptor T-cell death-associated gene 8 (TDAG8) facilitates tumor development by serving as an extracellular $\mathrm{pH}$ sensor. Proceedings of the National Academy of Sciences of the United States of America. 2010; 107: 17309-14.

13. Yuan FL, Wang HR, Zhao MD, Yuan W, Cao L, Duan PG, et al. Ovarian cancer $\mathrm{G}$ protein-coupled receptor 1 is involved in acid-induced apoptosis of endplate chondrocytes in intervertebral discs. Journal of bone and mineral research : the official journal of the American Society for Bone and Mineral Research. 2014; 29: 67-77.

14. Kottyan LC, Collier AR, Cao KH, Niese KA, Hedgebeth M, Radu CG, et al. Eosinophil viability is increased by acidic $\mathrm{pH}$ in a cAMP- and GPR65-dependent manner. Blood. 2009; 114: 2774-82.

15. Carswell KS, Papoutsakis ET. Extracellular pH affects the proliferation of cultured human $\mathrm{T}$ cells and their expression of the interleukin-2 receptor. Journal of immunotherapy. 2000; 23: 669-74.

16. Wyder L, Suply T, Ricoux B, Billy E, Schnell C, Baumgarten BU, et al. Reduced pathological angiogenesis and tumor growth in mice lacking GPR4, a proton sensing receptor. Angiogenesis. 2011; 14: 533-44.

17. Mogi C, Nakakura T, Okajima F. Role of extracellular proton-sensing OGR1 in regulation of insulin secretion and pancreatic beta-cell functions. Endocrine journal. 2014; 61: 101-10. 
18. Murakami N, Yokomizo T, Okuno T, Shimizu T. G2A is a proton-sensing G-protein-coupled receptor antagonized by lysophosphatidylcholine. The Journal of biological chemistry. 2004; 279: 42484-91.

19. Ludwig MG, Vanek M, Guerini D, Gasser JA, Jones CE, Junker U, et al. Proton-sensing G-protein-coupled receptors. Nature. 2003; 425: 93-8.

20. Frasch SC, Fernandez-Boyanapalli RF, Berry KZ, Leslie CC, Bonventre JV, Murphy RC, et al. Signaling via macrophage G2A enhances efferocytosis of dying neutrophils by augmentation of Rac activity. The Journal of biological chemistry. 2011; 286: 12108-22.

21. Okajima F. Regulation of inflammation by extracellular acidification and proton-sensing GPCRs. Cellular signalling. 2013; 25: 2263-71.

22. Tobo M, Tomura H, Mogi C, Wang JQ, Liu JP, Komachi M, et al. Previously postulated "ligand-independent" signaling of GPR4 is mediated through proton-sensing mechanisms. Cellular signalling. 2007; 19: 1745-53.

23. Liu JP, Nakakura T, Tomura H, Tobo M, Mogi C, Wang JQ, et al. Each one of certain histidine residues in G-protein-coupled receptor GPR4 is critical for extracellular proton-induced stimulation of multiple G-protein-signaling pathways. Pharmacological research : the official journal of the Italian Pharmacological Society. 2010; 61: 499-505.

24. Dupont S, Morsut L, Aragona M, Enzo E, Giulitti S, Cordenonsi M, et al. Role of YAP/TAZ in mechanotransduction. Nature. 2011; 474: 179-83.

25. Yu FX, Zhao B, Panupinthu N, Jewell JL, Lian I, Wang LH, et al. Regulation of the Hippo-YAP pathway by G-protein-coupled receptor signaling. Cell. 2012; 150: 780-91.

26. Dong J, Feldmann G, Huang J, Wu S, Zhang N, Comerford SA, et al. Elucidation of a universal size-control mechanism in Drosophila and mammals. Cell. 2007; 130: 1120-33.

27. Hao Y, Chun A, Cheung K, Rashidi B, Yang X. Tumor suppressor LATS1 is a negative regulator of oncogene YAP. The Journal of biological chemistry. 2008; 283: 5496-509.

28. Zhao B, Wei X, Li W, Udan RS, Yang $\mathrm{Q}$ Kim J, et al. Inactivation of YAP oncoprotein by the Hippo pathway is involved in cell contact inhibition and tissue growth control. Genes \& development. 2007; 21: 2747-61.

29. Zhao B, Ye X, Yu J, Li L, Li W, Li S, et al. TEAD mediates YAP-dependent gene induction and growth control. Genes \& development. 2008; 22: 1962-71.

30. Yimlamai D, Christodoulou C, Galli GG, Yanger K, Pepe-Mooney B, Gurung B, et al. Hippo pathway activity influences liver cell fate. Cell. 2014; 157: 1324-38.

31. Sorrentino G, Ruggeri N, Specchia V, Cordenonsi M, Mano M, Dupont S, et al. Metabolic control of YAP and TAZ by the mevalonate pathway. Nature cell biology. 2014; 16: 357-66.

32. Haskins JW, Nguyen DX, Stern DF. Neuregulin 1-activated ERBB4 interacts with YAP to induce Hippo pathway target genes and promote cell migration. Science signaling. 2014; 7: ra116.

33. Zhao H, Huang A, Li P, Quan Y, Feng B, Chen X, et al. E2A suppresses invasion and migration by targeting YAP in colorectal cancer cells. Journal of translational medicine. 2013; 11: 317.

34. Azzolin L, Panciera T, Soligo S, Enzo E, Bicciato S, Dupont S, et al. YAP/TAZ incorporation in the beta-catenin destruction complex orchestrates the Wnt response. Cell. 2014; 158: 157-70. 